\title{
A Critical Review of Theoretical Aspects of Strategic Planning and Firm Performance
}

\author{
Nabil Tarifi \\ Jeddah International College, Jeddah, Saudi Arabia \\ Email:ntarifi@hotmail.com
}

How to cite this paper: Tarifi, N. (2021). A Critical Review of Theoretical Aspects of Strategic Planning and Firm Performance. Open Journal of Business and Management, 9, 1980-1996.

https://doi.org/10.4236/ojbm.2021.94107

Received: May 20, 2021

Accepted: July 25, 2021

Published: July 28, 2021

Copyright (อ 2021 by author(s) and Scientific Research Publishing Inc. This work is licensed under the Creative Commons Attribution International License (CC BY 4.0).

http://creativecommons.org/licenses/by/4.0/ (c) (i) Open Access

\begin{abstract}
Strategic planning is critical in the management of an organisation due to the essential role it plays in leading the organisation into the identification of strategic plan to be used by the organisation through focusing the issues within the organisation, evaluating their effects while considering the organisational operations and developing alternative measures and tactics so as to ensure that the organisation earns competitive advantage as discussed in the paper. The dependence of the strategic planning and the performance of the firm is also notable with all the goals in the strategic planning, leading to influence the performance of the organisation. The paper uses elements of the strategic plan including the mission and the vision, the core values, the strengths, the weaknesses, the opportunities and the threats as well as the strategies, with an inclusion of the objectives and the operation tactics to review the strategic planning and the organisational performance. Qualitative methods are used to collect and analyse the secondary data from review past studies and reports. The study finds strategic planning significantly depending on the analysed elements of the strategic planning in achieving the outcome. The elements also play a critical role in aligning the organisation towards working on a specific organisational strategic planning process to ensure all stakeholders are focused on a common goal that determines the performance of the firm.
\end{abstract}

\section{Keywords}

Organisational Performance, Strategic Planning, Organisational Strategies, Decision-Making, Competitive Advantage, Organisational Goals

\section{Introduction}

Strategic planning is expressed as the process of guiding the organisational stakeholders in realising the envisioned future of the organisation and creates the ne- 
cessary developmental procedures, actions and operations that enhance the performance of the organisation (Wells \& Doherty, 1994). The strategic planning activities are therefore critical in determining the growth and development of an organisation which translate to the success of the firm. In 2011, Forbes noted ten reasons that contribute to the failure of a strategic plan which was outlined from the entire strategic planning process. In (Aileron, 2011) Forbes article, having a plan for plan's sake is among the great causes of strategic plan failure, whereby a strategic plan is developed by an organisation because an organisation is characterised by having a plan. Organisational planning teams must perceive and interpret the business environment changes to retain the competitive advantage of the firm otherwise the strategic performance failure is due to the inability to understand the environment and not focusing on the result. Partial commitment also plays a significant role in the success of the strategic plan and the fact of not having the required people and resources cause failure. It is a must nowadays to delegate the right people to execute the suitable plan, and not to rely on people who are not committed or have inadequate knowledge of executing the strategy in tough circumstances.

Aileron (2011) also noted that writing and shelving the plan is a great strategic plan performance failure as well as the inability or unwillingness to change with the market conditions changes. Another cause of failure is poor leadership, related to those people who are not eligible for making tough and developmental oriented operations recommended on the strategic plan. The ignorance of facts' reality and assumptions of the marketplace and lack of accountability as a result of escapism or lack of commitment of resources in the right ineffective operations are all leading causes. Finally, the setting of unrealistic goals creates a lack of organisational focus due to unmanageable goals and objectives (Aileron, 2011).

The benefits of strategic planning in an organisation are evident in every individual or department through its impact on organisational performance. Wells \& Doherty (1994) note that strategic planning not only creates an organisation's future but also create a framework for efforts improvements. The benefits as expressed provide the basis for the planning and organisational specific scrutiny to develop a framework for decision-making (Moody, n.d.). Strategic planning also provides structured organisational plans that are effective in guiding the timelines, evaluations and assignments which form the additional importance of strategic planning as assisting in the creation of benchmarking and monitoring of the performance (Moody, n.d.). It also allows the leaders to learn through the evaluation of the performance of the plan or the evaluation of challenges affecting the organisation. Hence, gain the ability to analyse and solve critical problems within the firm (Wells \& Doherty, 1994). Strategic planning can be explained to provide the organisation with a platform for optimisation of the systems to achieve the set goals with the application of organisational values with the main aim as creating a competitive advantage that position the organisation 
either on development or profit-making (Wells \& Doherty, 1994).

The paper identifies the importance of strategic planning in determining the performance of the firm, as well as the reasons that lead to strategic planning failure in an organisation. Thus, it seeks to develop a critical review of the aspects of strategic planning that influence the performance of the firm. The evaluation outlines aspects such as the mission and vision of the organisation, core values, strengths, weaknesses, opportunities and threats as well as the objectives, strategies and operational tactics. The elements assist in creating a theoretical perspective of the influence strategic planning has on the performance of the organisation. The study informs the process of the organisational planning by identifying aspects to consider in developing the concept. However, the study faces the challenge applying the conclusions drawn from the study to confirm the effectiveness of the study and analyse the challenges that may arise.

\section{Literature Review}

Different scholars have developed different perceptions of strategic planning as applied in an organisational set-up. It is a process of investigating the organisational future and the identification of issues and trends that align with the priorities of the organisation (United Nations, 2019). The description creates the analysis of organisational aims in teams, divisions and units to a high-level strategy that assures high chances of realising goals. The (United Nations, 2019) states that good strategic planning initiates focus, accountability and results.

Maleka (2014) creates an impression that strategic management develops a blueprint thatthe organisation uses to ensure that their goals are realised. The study notes that when an organisation creates a strategic plan, the management has identified specific objectives they wish to satisfy through the execution of the strategic plan. The document outlining the strategic plan communicates the organisation goals, required actions for the fulfilment of the goals and critical elements and planning procedure. Thus, Maleka (2014) describes an organisational management activity as consisting of setting priorities, focusing resources, strengthening operations and ensuring the organisational stakeholders and employees focus on realising the common goals, establishing results and adjusting the organisation directions according to the changing environment.

Strategic planning according to The Enterprise Foundation (1999), states that it is an essential process that orient an organisation within its mission. It finds the framework to make critical decisions on the way of allocating the resources, challenges and taking advantages of the opportunities for the development of the organisation. The report notes that strategic planning is a critical process in the success of the organisation through informing the priorities, obstacles and opportunities, which limit or enable an organisation to carry out the mission.

Additionally, the National Minority AIDS Council (NMAC), (2016) strategic planning shares the organisation's vision with both internal and external audience, clarifies specific missions, identify stakeholders, consumers and clients, 
specifying strengths and weaknesses, evaluates the relevant environment for potential risks as well as creating the context for making choices. Therefore, National Minority AIDS Council (NMAC), (2016) reports that according to the definition of Bryson, strategic management is a disciplined effect of enabling fundamental decisions and operations that guide and shape an organisation in terms of what it does and why the organisation do it while focusing on the future.

\subsection{Elements of Strategic Planning}

Strategic planning can be expressed through different schools of thoughts from different understandings as well as the aspects applied in its implementation. as explained by (Berzins, 2010) design school entails the conception process that seeks to balance the strengths, weaknesses, opportunities and threats. The planning school relates to the principle of strategic planning into specific steps. The perception from the positioning school of thought is due to the analytical process in concepts such as value chain, strategic groups, among others while the entrepreneurial school refer to the future projection of the strategic plan. The cognitive school of thought is derived from the strategic planning process being an intellectual process that deals with research and strategic concepts to develop a constructive strategy. Similarly, there is a learning school duct to the process of the unpredictability of the performance of the developed strategies. The configuration school characterise the dynamic transformation process while the environment school is due to the reactive orientation to fit in the market changes (Berzins, 2010). The school of thoughts does not only bring out the importance of strategic planning to the organisation but it also creates the impression under which an effective strategic plan should guide a firm. The strategic plan should have critical aspects to effectively satisfy all the school of thoughts explained.

\subsection{Mission and Vision of an Organisation}

The mission and vision are critical elements in strategic planning that bring out the expected performance standards concerning the organisational goals. The organisational mission and vision are often confusing in terms of what each represents and express in an organisation. The mission statement as defined by (Bowen, 2018) are more specific and direct to an organisational focus on competitive advantage such that it shows the priority of activities. Thus, the report explains the mission of an organisation as the quest for an organisational goal that uniquely derives a competitive advantage from the description of specific strengths and available opportunities in comparison with the competitors in consideration of the organisational values. On the other hand, the vision is future-oriented, describing the position that an organisation is expected to have in the market at a specific time. It is understood to be the organisational goals in a long-term expression, which offer strategic alignment of the goal for the normative world. It, therefore, pushes for innovation, commitment and motivation to 
reduce the barriers that could hinder the achievement of the goals (Bowen, 2018). The vision statement hence, expresses a long-term position that determines where the organisation would wish to be within the competitive environment (Bowen, 2018).

Papulova (2014) notes the mission and vision as aspects of strategy formulation in strategic management, which is strategic planning. The purpose of the mission and vision is to lead the firm in the desired strategic position by guiding the organisation into the future by expressing about the future as well as the organisational future. They express their intention by creating obligational demands to be met rather than the creation of a prediction (Papulova, 2014). Thus, in the development of a mission or vision, the emphasis is more on promoting the intentions, the actions to be taken and the results wished to be achieved.

Taiwo, Lawal, \& Agwu (2016) outline clearly the differences between the mission statement and vision statement despite the close similarity in guiding the organisation towards common goals. The differences can be seen in about whereby the mission statement describes how the goals will be achieved while the vision statement summarises where the organisation want to be in the future. The mission statement answers the stakeholders on the question of what to do while the vision statement answers the question of where the aim is to be in the future. In terms of time the article by Taiwo, Lawal, \& Agwu (2016) state that mission focus on present headed to future, while vision focus about the future. Finally, the features in an effective mission statement involve the reasoning and guidance of organisational ethics while the vision statement is required to the concise, clear and unambiguous to ensure easy adjustments to the values and aspirations.

The Components and Development of Mission and Vision Statements As previously stated, the mission statement should be unambiguous, clear and concise to both the market and stakeholders. Additionally, it should communicate, infuse, instruct, tolerate and provide a conducive environment that creates bonding within the organisation (Taiwo, Lawal, \& Agwu, 2016). Additionally, the mission statement should focus on nine elements including the market, products, customers, technology, growth, profitability and the concern for survival. The vision statement should focus on elements such as the philosophy, employees' concerns, customers, market, self-concept, products, technology, survival and profitability as well as the public image of the firm (Taiwo, Lawal, \& Agwu, 2016).

In the development of a vision statement, the management aims at easilyunderstanding positive, motivational, attractive, challenging, easy to remember and future-oriented statement (Papulova, 2014). Thus, the concept of developing of vision and a vision statement involves the discovery of the vision in the intuition process, which is described by Taiwo, Lawal, \& Agwu (2016) to happen unintentionally in form of a perceived dream. The next step involves a team approach 
that involves the generation of ideas, views and opinions that improve innovation and creativity. Then the rational approach that calls for logic thinking and creation of hypothesis, comparisons, deductions and engaging research which lead to the final step of adaptation of the vision.

The mission statement is developed through the focus on the target audience of the organisation's mission statement (Papulova, 2014). The mission statement can address different audiences through the tone, length, communication and visibility of the statement. Papulova (2014) notes lack a specific procedure, formulae or pattern of formulating a mission statement, but rather focus on the nine components of a mission statement outlined earlier in the paper while focusing on the factors outlined by Bowen (2018) including the vision of the founder, vision statement, research, ethical values and leadership and management style.

\subsection{Core Values of an Organisation}

The scholarly review of organisational core values reveals that it is essential for an organisation to agree upon within the organisation broader circle and build a consensus that makes communication critical in influencing how people carry out their tasks and roles within a firm (Gorenak \& Kosir, 2012). The definition of the organisational core values according to Lunden \& Utberg (2017) report shows it is an enduring belief that particular conduct or existence of socially or personally preferred over the opposite mode of conduct. Also, the report expresses the definition of Hofstede that express value as a broad tendency that is preferred in a specific state of affairs compared to others but deviates from the attitudes which show practical outcome through job satisfaction whereas the concept of organisational value revolves around interests without the compulsory achievement of practical results or conclusions (Lunden \& Utberg, 2017). Thus, the organisational core values could be understood to be the values embedded deeply in the organisation and have guided the operations for a long time, hence the heart of the organisation.

Organisational core values must be understood (Lunden \& Utberg, 2017) by all stakeholders within the organisation because they are believed by firms to be morally worth in defining the organisational behaviour (Gorenak \& Kosir, 2012). The core values for a successful organisation are described by Gorenak \& Kosir (2012) to be desirable such that they are indicative of the organisational aspirations and organisational future aspects. Also, it is characterised by being stable that they endure different environments with slight adjustment influenced by the change in the environment and the core values should be organised in a specific hierarchy such that the values desirability degree is expressed to the workers. Still, core values should be developed from the outcome of the social, historical and individual interactions within the organisation.

Regardless of the characteristics, organisational core values are subject to specific features such as preference, allowing the possibility to evaluate the rela- 
tionship between the behaviours and the behavioural systems and develop normative regulations. The core values should express the element of permanency and openness to change to complement the organisational goals. Another critical feature in organisational core value is the ability to create a behaviour and manage specific actions and situations to the organisational standards. Values should also be able to set standards and develop the criteria to recruit new talents based on the potential to meet the standards and they should also be capable of the outcome of an individual and others within the organisation by not only checking whether the workers meet the goals but also motivating the ideal behaviour for performance within the organisation.

Importance of Organisational Core Values in the Organisational Performance

\section{Employee Engagement}

The employee engagement impacts both the organisation and the employees (Osborne \& Hammound, 2017) whereby employees could use contract agreement provisions to hinder the realisation of the organisational objectives and goals, thus management utilises the employee engagement strategies to leverage the employees. The core values in an organisation seek to establish the framework for the standards for the performance of the employees while Osborne \& Hammound (2017) notes that when an organisation establishes high expectation levels and frequent reviews of performance then employees' cooperation and participation is increased. The study (Osborne \& Hammound, 2017) notes that employee engagement is among the greatest challenges in the organisations today due to the complexities and strict regulations within the organisations as a result of scarcity of resources that have led to increased thinking about the reduction of expenditure and increase in efficiency and productivity.

\section{Employee Retention and Talent Acquisition}

Kossivi, Xu, \& Kalgora (2016) notes that employees are essential resources in a firm and the most valuable asset as well. Hence it is essential to retain the employees as well as attract quality talent to the firm. Employee retention involves organisational strategic actions to ensure the employees are focused and motivated to maximum productivity and remaining employed for the organisation's benefits by the provision of effective communication to improve commitment and workforce support (Kaur, 2017). Regarding the concept of core values and the roles it plays in an organisation, the core values build an environment and help align the employees identify with the culture of the organisation, thereby promoting the employee retention and improving the performance of the firm.

\section{Customer Satisfaction}

The customers are essential to the performance of the organisation and are critical in the development and existence of the firm, hence the necessity to meet the expectation of the customer (Biesok \& Wyrod-Wrobel, 2011). The customer's satisfaction has a different definition based on the perspective of either the firm, customer, product or the employees. However, a more specific definition 
considers customer satisfaction as a function of a convergence of prospects with the perceived approach of action of the product by the customer (Biesok \& Wyrod-Wrobel, 2011). For a customer to feel satisfied, Khadka \& Maharjan (2017) notes that they check the value of the total service which require the collaboration of all organisational department in offering services to the satisfaction of the customer. Therefore, the performance of the firm which is influenced by the level of customer satisfaction is also dependent on the core values to ensure the firm retain customers.

\section{Growth and Stability of the Organisation}

The growth and stability of an organisation are critical in ensuring the efficient workflow and the organisational stakeholders work towards a common goal. The factor is significantly impacted by the core values in the firm as indicated by Appelbaum, Cameron, Ensink, \& Hazarika (2017) that the shared values play a critical role in guiding and shaping the employees' attitude and behaviour which is likely to influence the performance of the organisation. Equally, it is recommendable for the top management to promote organisational core values for the adopted change in the organisation to increase the chances of attaining the level of commitment targeted (Appelbaum, Cameron, Ensink, \& Hazari$\mathrm{ka}, 2017)$. The importance of the core values in promoting the growth of the organisation is evident in its importance in consideration by the management when implementing change. It is stated that they must pay attention to harmonising the change with several elements among them the organisational values and beliefs (Rizescu \& Tileaga, 2016).

\subsection{Strengths, Weaknesses, Opportunities and Threats of a Firm}

The importance of the external environment in influencing strategic planning is emphasised when relation various aspects of the external market to the business such as economic condition, political climate and market (Odera, 2014). He notes that the importance of the environment in the process of formulation of strategies is because it is the environment that drives the firm that the firm continuously responds to and adjusts in particular periods. The strength, weakness, opportunities and threats (SWOT) analysis is used in the evaluation of the environment. The analysis divides the environment into two including the internal and external environments. The internal environment analysis identifies the strengths and weaknesses through the identification of resources, core competencies, capabilities and organisational competitive advantage. The external environment is carried out through the analysis of opportunities and threats by consideration of the resources of the competitors and the environment of the sector (Sammut-Bonnici \& Galea, 2014). SWOT is described as applicable by business corporations, non-profit organisations as well as government departments in performing business planning, competitor, strategic planning and marketing development of which happens at a very early age of the strategic planning process (Tuncay, 2015). 
Strategic planning helps a firm in making-decision on the resources allocation to realise the goals. It is therefore crucial in determining successful strategic management due to its nature of being a continuous process of creation, implementation and evaluation of decisions that promote the organisation's objective. In the evaluation to inform the decision, SWOT analysis develops four dimensions (Gurel \& Tat, 2017). Strengths express the characteristic that adds value to a product or service to make it earn a more competitive advantage over the others. It evaluates the situations and features that make an organisation efficient and effective in comparison to the competitors (Gurel \& Tat, 2017). Examples of the strengths an organisation could consider in the SWOT analysis evaluation is the financial strengths through the robust balance sheet, excellent credit rating and cash flow, the technological and production advantages, customer service advantages and the talents and experience of employees (Sarsby, 2012).

The weaknesses generally are the situations of not having or possessing inadequate resources necessary for doing something. In the organisation, it means that the available situations and ability capacities out the organisation in a disadvantageous position compared to the other organisations in the market (Gurel \& Tat, 2017). The aspect evaluates the negative performance of the organisation and what weakens the organisation against the competitors or what would lead to an organisation not being able to respond to the opportunities. Therefore, as noted by Pearce and Robinson, organisational weaknesses are the deficiencies and limitations in capabilities, skills and resources that hinder the effective performance of the organisation (Gurel \& Tat, 2017). The weaknesses could be observed from the evaluation of financial weaknesses like high debt ratios, outdated technology, poor communication and long durations of products and services delivery as well as inadequate skills or poor attitude of employees towards organisational roles (Sarsby, 2012).

In the external environment, opportunities in SWOT manage and control the available situations and conditions that are suitable for the excellent performance of activities of the organisation. They are the driving forces for an activity to occur, which lead it too have a favourable and positive characteristic in an organisation. Opportunities are all organisational factors and elements that attract positive outcome by allowing the organisation to utilise strengths effectively, manage the weaknesses for the good performance of the firm (Gurel \& Tat, 2017). They guide the strategic planning process in determining the measures to be taken to earn a competitive advantage for the perception of the market environment. It looks into aspects such as withdrawal of competitors from the market, arising social trends, innovations and legislation (Sarsby, 2012).

The threats as explained in the Gurel \& Tat (2017), represent the external conditions and situations that limit the actualisation of activities within the firm. It is a disadvantageous situation due to its characteristics of negativity towards the firm achieving its goals. An organisation usually has very little or no control of threats due to being created from the external sources of the organisation, 
hence the organisation can only manage or minimise the threats (Arslandere \& Ocal, 2016). The threats could be new competitors, hostile takeovers or restrictive regulations (Sarsby, 2012).

Earlier, the importance of having a well-guided strategic plan is laid out and following the composition of SWOT analysis. It establishes an excellent framework for formulating effective information for decision-making. Thus, SWOT analysis has the advantage of applying general perspectives and presenting general solutions. It drives the organisation from a broad view of the organisational environment to a specific area that creates a significant effect on the organisation (Gurel \& Tat, 2017). It is also an interactive analysis technique that guides into an evaluation of negative and positive aspects as well as analysis of micro and macro environments of an organisation. It is projected as a thinking model of analysis thus it enables the management to analysis through steps that could guide the strategic planning process into identifying the areas an organisation could be weak or threatened by the market (Gurel \& Tat, 2017).

The SWOT analysis provides an opportunity for group discussion about the strategy development and strategic position of the firm such that the developed strategy plan from the strategic planning process is understood by all stakeholders. The analysis allows for the integration of analytical levels therefore workers understand the development of the strategy and the areas to focus on to realise the objectives (Gurel \& Tat, 2017). However, it has some limitations such as the perception of "Weihrich" that the analysis of the external environment is not as essential as expressed in the SWOT analysis model due to lack of organisational control within the organisation and states that the comprehensive (Clardy, 2013). Also, SWOT analysis requires training and experience to obtain reliable information due to the requirement for systematic construction. Gurel \& Tat (2017) notes that SWOT analysis is not only time consuming not also costly for an organisation to undertake due to the long process of meetings and listing of the influential factors to the organisation.

\subsection{Objectives, Strategies and Operational Tactics}

In strategic planning, different strategies of ensuring the realisation of the objectives are adapted to improve on organisational tactics. Among the strategies is management by the objective that entails the process where senior and subordinate managers in a firm discuss and identify common goals, assign each the areas of responsibility and state the expected results, then use the expected results to guide the improvements and assess the contribution of members. The strategy is critical in providing a link between organisational objectives and the personal goals of the individual because all the organisational goals and objectives are formulated with the involvement of both the subordinate and the managers jointly (Nwafor-Orizu, Chinyere, \& Tochukwu, 2019). The strategy puts across the objective as the guide to all stakeholders hence the strategies are developed to help realise the objectives. The strategy of management at which all 
the human resources are guided by goals helps build efficient innovation and planning (Nwafor-Orizu, Chinyere, \& Tochukwu, 2019).

Based on the importance of the effective strategy and the focus towards the organisational objectives, Holdt (1995) identifies critical barriers that hinder the successful planning and the implementation of strategies. The barriers align with the organisational objectives and strategies or with the operational tactics of the firm. The barriers such as organisational failure to focus on the end goal but focus on the means, create the organisation to miss the expected results while lost in implementing the means. Also, the study notes a challenge of having the objective written but it does not include a clear method of arriving at the objective which shows the problem of lack of developing a precise strategy to support the achievement of the expected objectives. Thus, it explains that if a business aims at improving the performance, it must target on working towards a common goal that should be made clear, have timelines with practical set standards of achievement and have challenging characteristics to promote innovation.

Objectives are the outcomes of planned activities and they express the expected accomplishments and when they should qualify. A firm could focus on different fields such as profitability, efficient among others to ensure the profitability of the organisation or improvement of the environment in the organisation (Tapera, 2014). The study identifies the critical objectives to help frame objectives in the market is through managing risks, achieving efficiency and learning, adapting and innovation. On the other hand, developing strategy entails an alignment of the strategies according to different challenges such as how to grow the organisation, pleasing customers, outcompeting with rivals, response to changing market environment as well as achievement of strategic and financial objectives. The process of crafting a strategy involves selection from a list of strategies (Tapera, 2014). Thus, achieving an effective strategy, that is capable of providing a solution to stated problems. It follows four critical steps including reviewing the primary objectives and strategies then identification of the relevant range of the strategic alternatives that address the levels of strategy formulation. The third step according to Tapera (2014) is the evaluation of the pros and cons of the alternative feasible strategy to determine the effects and contributions to the organisational success. Finally, deciding on the strategy to be implemented.

\subsection{Importance of Strategy in an Organisation}

According to Ajagbe, Ojochide, Ekanem, Uduimoh, \& Akpan (2016) the importance of strategy to organisational success is exceptional, by focusing the organisation from being reactive to proactive, thus enablingthe implementation and the initiation of strategies that promote strategic planning. Organisational strategies create more commitment within the organisation towards the achievement of the objectives which promote organisational performance. If a strategy is well-crafted and the organisational problems were adequately analysed, it helps 
in improving the sales, productivity and profitability of a firm. Good strategies enable easy understanding of the operations in the organisation, which aid in SWOT analysis in troubleshooting and creating awareness of potential threats in the market. It also plays a critical role in the reduction of the resistance to change, a condition that negatively impacts the behaviour of workers in the firm due to misunderstanding of the goals (Ajagbe, Ojochide, Ekanem, Uduimoh, \& Akpan, 2016). The importance of strategy is experienced in the communication between the employees and the supervisors, which is significantly improved thus helps to clarify the objectives and overall organisational mission and vision in strategic planning (Tapera, 2014).

\subsection{Theoretical Framework}

The paper reviews the relationship and the influence between strategic management concept towards organisational performance. The study noted the Maleka, (2014) illustrate strategic planning as the roadmap for an organisation to meet its set goals. On the other hand, Berzins (2010) perceive the concept of strategic planning to influence organisational performance based on a specific school of thoughts, while strategic planning has critical elements that determine its effectiveness. Therefore, the study applies the elements of strategic planning in establishing the involvement of strategic planning concept in determining the performance of the organisation rather than the identified structure on the studies in the literature review section that perceive organisational performance to be driven by strategic planning process through the school of thoughts. It deviates from the specific elements involved in the strategic planning as the guide to organisational performance. The established gap is analysed through the provision of a conceptual definition of strategic planning and critical evaluation of each element of the strategic plan including the mission and vision, core values, SWOT, and organisational objectives.

\section{Methodology}

The research basically investigates specific information and knowledge on a specific subject which is termed by Mishra \& Alok (2017) as systematic investigation. The study hence seeks to review the aspects of strategic planning and firm performance by comprehension of the strategic plan elements in promoting the performance of a firm. Mishra \& Alok (2017) also notes that research methodology is the science of studying the way of carrying out research systematically. Hence, the scientific approach adopted to conduct the research is the methodology. The study adopts a specific qualitative research method approach and is an exploratory type of research. Qualitative research methodology looks critically at non-numerical data to analyse a particular phenomenon. It is best preferable for establishing the potential relationships between variables without quantification of the variables (Goundar, 2012). The study reviews the existing theoretical information about strategic planning and organisational performance. Exploratory 
research creates and explains theoretical literature already in existence (Mishra \& Alok, 2017). Still, it is carried out to investigate the future possibilities of carrying out specific studies (Goundar, 2012), which derive the similarity with the study which identifies the link of the existing studies on strategic planning and firm performance. The data collected is secondary data obtained from credible sources such as internationally recognised journals, accredited books and recognised and credible international media reports. Thus, the data analysed is credible, reliable and valid for consideration to guide in making a reliable conclusion on the topic as discussed in the appendix. The study requires a procedural flow of activities to process relevant data as shown below.

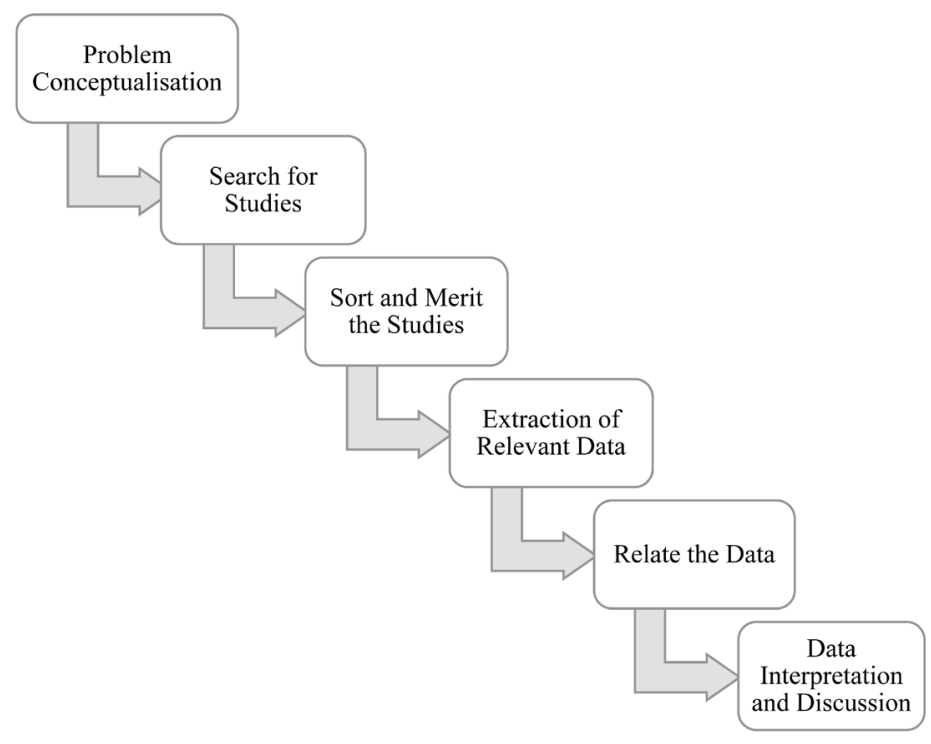

\section{Discussion and Interpretation}

The study identifies the relationships or dependency between the strategic planning and the organisational performance and elements of the strategic plan. With reference to strategic planning to be defined from a different school of thought as evident in (National Minority AIDS Council (NMAC), (Maleka, 2014), the stand out explanation of strategic planningis the process of focusing on the issues within the organisation, evaluating their effects while considering the organisational operations and developing alternative measures and tactics of ensuring the organisation earns competitive advantage. Strategic planning focus is brought out by different studies analysed to focus on the performance of the organisation, hence a conclusion can be made that it develops a strategic plan that positions an organisation towards growth and development.

The mission and vision of a firm have been expressed to be essential in promoting the goals of an organisation in the study outlined in the literature review as (Taiwo, Lawal, \& Agwu, 2016). They focus on the future expectation of the firm hence guide the organisational short-term goals in the standards of the goals to be achieved. The mission and vision set up what the organisation should 
work on achieving by setting general obligations of the organisations which set the framework of a strategic planning process. It is thus the reason why the mission and vision statementsare supposed to be clear, concise and easy to understand in order to communicate the role of each resource within the firm and instruct the managers on the effective allocation of resources.

The mission is described to create the perception of the order of activities within a firm and vision express the measurement of success of the firm in a specified duration by stating the expected position in the reviewed study by (Papulova, 2014). Both mission and mission of the organisation are formulated with the organisational performance goals and inspire the selection of approaches in strategic planning to achieve the required performance. Thus, it is a correct interpretation to state that the strategic planning and organisational performance depend on the organisational mission and vision for competitive advantage and positive overall outcome respectively.

Considering another element of the strategic plan, the core values of an organisation, that prescribe the conduct within the organisation, various observations can be made on its relation with the organisational strategic planning and performance. The express of strategic planning from the cognitive school of thought as an intellectual process the seeks to create constructive organisational approaches, captures the core values as the key factor of enhancing the strategic concepts to solid strategies reliable for the growth of the organisation with reference to study by Berzins (2010). Among the listed characteristics of success-oriented core values of an organisation is the ability to influence adjustments to the strategies and change with the slightest effect on the organisation's vision and mission in the review studies by (Gorenak \& Kosir, 2012; Lunden \& Utberg, 2017). Thus, the strategic planning process is significantly impacted by the core values of the organisation to ensure they align the developed strategies with the available core values. For instance, the strategic planning process must be able to ensure it does not alter the established framework on employee engagement to avoid creating customer dissatisfaction, which leads to employees turn over and difficulty in talent acquisition. Therefore, for growth and stability of an organisation, which results in excellent strategic planning and focus on the performance of the organisation is significantly influenced by the organisational core values.

The strengths, weaknesses, opportunities and threats of a firm form the environment an organisation thrive under hence used in SWOT analysis. The study with reference to studies by Odera (2014), Sammut-Bonnici \& Galea, (2014), Gurel \& Tat (2017) notes the significance of environmental evaluation in the process of strategies formulation. The SWOT analysis is applicable in the development of a strategy plan hence forms an essential aspect of decision-making on the strategic planning process. The key role of SWOT analysis is to develop a competitive advantage for the organisation as strengths define the features that organisation could utilize for effective performance at ease, the weaknesses show 
the incapability of the firm, the opportunities are the gaps in the market that an organisation could prosper in then the threats are the features out of control impacting the performance of the organisation. All the four dimensions discussed to address the efforts of the organisation towards performance by developing interactive situations that later develop strategies relatable to everyone within the organisation. Strategic planning requires the collaboration of all stakeholders to develop an excellent working environment that supports positive performance, the SWOT analysis by introducing group discussions on the challenges within the organisation promotes control of the organisation towards the organisational objectives. Hence, a conclusion can be drawn that the SWOT analysis not only brings an understanding of the organisation status but also builds an environment supportive of the excellence of a firm.

The strategies and the objectives could be perceived as the end result of the strategic planning process but they play a critical role in strategic planning and organisational performance as noted that objectives form short term goals that align with common organizational goals in reference to the reviewed studies by Tapera (2014), Holdt (1995), Nwafor-Orizu, Chinyere, \& Tochukwu (2019). It is notable that an organisation could have various objectives with different strategies to facilitate their achievements as derived from the study by Tapera (2014). The strategy is therefore the means of ensuring the goals are achieved and the overall organisational goals are met. Therefore, they serve a critical role in strategic planning. The objectives which could target ensuring customer satisfaction, employee engagement an improving efficiency in production all are oriented toward the performance of the organisation. The strategies link all the objectives towards a common goal. Hence, the strategies and objectives should not only be considered as the absolute end results but also should be adopted as the guide in strategic planning for the expected performance.

\section{Conclusion}

Based on the discussion, the study concludes that in as much as the strategic planning process through the school of thoughts that are perceived to create in an organisation, the specific element of strategic planning also plays a critical role in establishing the roadmap to the organisational achievement of its goals. After the discussion, the study develops the definition of strategic planning as the process of identifying organisational issues in terms of strengths, weaknesses, opportunities and threats, analysis of the issues and their effects on the firm and coming up with measures and approaches that will drive the organisation to gain competitive advantage. The mission and vision element of the organisational strategic planning inspires the selection of approaches and measures thus influence the performance of the organisation. The core values help in adjusting the approaches and measures to align with the culture of the organisation to ensure the success of the strategy. The strengths, weaknesses, opportunities and threats through its analysis, help in establishing the environment the organisation oper- 
ate in both internally and externally and enable building or improving the environment to promote organisational performance.

\section{Conflicts of Interest}

The author declares no conflicts of interest regarding the publication of this paper.

\section{References}

Aileron (2011). 10 Reasons Why Strategic Plan Fail. Forbes.

Ajagbe, M. A., Ojochide, F. P., Ekanem, E. U., Uduimoh, A. A., \& Akpan, S. E. (2016). Business Strategy as a Contributor to Organisational Performance. International Journal of Advanced Academic Research, 2, 1-19.

Appelbaum, S., Cameron, A., Ensink, F., \& Hazarika, J. (2017). Factors that Impact the Success of an Organisational Change: A Case Study Analysis. Industrial and Commercial Training, 49, 213-230. https://doi.org/10.1108/ICT-02-2017-0006

Arslandere, M., \& Ocal, Y. (2016). SWOT Analysis as a Tool for Strategic Managment and an Implementation in a Firm in Machine Industry. 1st International Academic Research Congress 2016, Antalya, November 2016, 3438-3445.

Berzins, G. (2010). Strategic Planning. University of Latvia.

Biesok, G., \& Wyrod-Wrobel, J. (2011). Customer Satisfaction: Meaning and Methods of Measuring. In G. Biesok, \& J. Wyrod-Wrobel (Eds.), Marketing and Logistic Problems in the Management of Organization (pp. 23-41). Wydawnictwo Naukowe Akademii Techniczno-Humanistycznej w Bielsku-Białej.

Bowen, S. A. (2018). Mission and Vision. University of South Carolina. https://doi.org/10.1002/9781119010722.iesc0111

Clardy, A. (2013). Strengths vs Strong Position: Rethinking the Nature of SWOT Analysis. Modern Management Science \& Engineering, 1, 100-122.

Gorenak, M., \& Kosir, S. (2012). The Importance of Organisational Values for Organisation. Management Knowledge and Learning International Conference, Make Learn, 563-569.

Goundar, S. (2012). Chapter 3: Research Methodology and Research Method. In S. Goundar (Ed.), Cloud Computing. Research Gate Publications.

Gurel, E., \& Tat, M. (2017). SWOT Analysis: A Theoretical Review. The Journal of International Social Research, 10, 994-1006.

Holdt, J. (1995). A Framework for Achieving Organisational Objectives through Integrated Performence Management. Rand Afrikaans University.

Kaur, R. (2017). Employee Retention Models and Factors Affecting Employees Retention in IT Companies. International Journal of Business Administration and Management, 7, 161-174.

Khadka, K., \& Maharjan, S. (2017). Customer Satisfaction and Customer Loyalty. Centria Univeristy of Applied Sciences.

Kossivi, B., Xu, M., \& Kalgora, B. (2016). Study on Determining Factors of Employee Retention. Open Journal of Social Sciences, 4, 261-268.

https://doi.org/10.4236/jss.2016.45029

Lunden, J., \& Utberg, A. (2017). Corporate Values: Empty Words or a Crucial Part of an Organisation: A Case Study Analysing the Challenges of Establishing and Implement- 
ing Corporate Values. University of Gothenburg.

Maleka, S. (2014). Strategic Management and Strategic Planning Process. DTPS Strategic Planning \& Monitoring, Pretoria, March 2014.

Mishra, S. B., \& Alok, S. (2017). Handbook of Research Methodology. Educreation.

Moody, D. W. (n.d.). Importance of Strategic Planning. King George County Department of Fire, Rescue and Emergency Services.

National Minority AIDS Council (NMAC) (2016). Strategic Planning. National Minority AIDS Council.

Nwafor-Orizu, I., Chinyere, O. M., \& Tochukwu, E. K. (2019). Management by Objectives as an Effective Tool for Enhancing Organisational Productivity. Department of Public Administration and Local Government.

Odera, P. A. (2014). Factors Influencing Strategic Planning Process by Major Sugar Producing Firms in Kenya. University of Nairobi.

Osborne, S., \& Hammound, M. S. (2017). Effective Employee Engagement in the Workplace. International Journal of Applied Management and Technology, 16, 50-57. https://doi.org/10.5590/IJAMT.2017.16.1.04

Papulova, Z. (2014). The Significance of Vision and Mission Development for Enterprises in Slovak Republic. Journal of Econimics, Business and Management, 2, 12-16. https://doi.org/10.7763/JOEBM.2014.V2.90

Rizescu, A., \& Tileaga, C. (2016). Factors Influenceing Continuous Organisational Change. Journal of Defense Resources Management, 7, 139-144.

Sammut-Bonnici, T., \& Galea, D. (2014). SWOT Analysis. In T. Sammut-Bonnici, \& D. Galea (Eds.), Wiley Encyclopedia of Management. John Wiley \& Sons, Ltd. https://doi.org/10.1002/9781118785317.weom120103

Sarsby, A. (2012). A Useful Guide to SWOT Analysis. Pansophic Online.

Taiwo, A. A., Lawal, F. A., \& Agwu, M. E. (2016). Vision and Mission in Organisation: Myth or Heuristic Device? The International Journal of Business \& Management, 4, 127-134.

Tapera, J. (2014). The Importance of Strategic Management to Business Organisations. The International Journal's: Research Journal of Social Science \& Management, 3, 122131.

The Enterprise Foundation (1999). Effective Strategic Planning. The Enterprise Foundation.

Tuncay, M. (2015). SWOT Analysis in Strategic Management and a Sample Application in Public. Munich Personal Repec Archive.

United Nations (2019). Strategic Planning Guide for Managers. https://hr.un.org/sites/hr.un.org/files/4.5.1.6 Strategic\%20Planning\%20Guide 0.pdf

Wells, D. L., \& Doherty, L. M. (1994). A Handbook for Strategic Planning. Department of the Navy Total Quality Leadership Office. 